\title{
Magnetic layer formation on plasma nitrided CoCrMo alloy
}

\author{
O. Öztürk ${ }^{\mathrm{a}, *}$, S. Okur ${ }^{\mathrm{a}}$, L. Pichon ${ }^{\mathrm{b}}$, M.O. Liedke ${ }^{\mathrm{c}}$, J.P. Riviere ${ }^{\mathrm{b}}$ \\ a Department of Physics, Izmir Institute of Technology, Urla 35430, Izmir, Turkey \\ b Institute PPRIME UPR3346 CNRS, ENSMA, Universite de Poitiers, Futuroscope-Chasseneuil, France \\ ${ }^{c}$ Institute of Ion Beam Physics and Materials Research, Forschungszentrum Dresden-Rossendorf, P.O. Box 510119, D-01314 Dresden, Germany
}

\section{A R T I C L E I N F O}

\section{Article history:}

Received 15 September 2010

Accepted in revised form 20 January 2011

Available online 27 January 2011

\section{Keywords:}

CoCrMo alloy

Expanded austenite structure

Plasma nitriding

Ferromagnetism

MOKE

MFM

\begin{abstract}
A B S T R A C T
In this study structural and magnetic character of the expanded austenite phase $\left(\gamma_{\mathrm{N}}\right)$ layer formed on a medical grade CoCrMo alloy by a low-pressure Radio-Frequency plasma nitriding process was investigated. The formation of the expanded austenite phase is facilitated at a substrate temperature near $400{ }^{\circ} \mathrm{C}$ for $1,2,4$, 6 and $20 \mathrm{~h}$ under a gas mixture of $60 \% \mathrm{~N}_{2}-40 \% \mathrm{H}_{2}$. The magnetic state of the $\gamma_{\mathrm{N}}$ layers was determined by a surface sensitive technique, magneto-optic Kerr effect (MOKE), and with a scanning probe microscope in magnetic force mode (MFM). Strong evidence for the ferromagnetic nature of the $\gamma_{\mathrm{N}^{-}}(\mathrm{Co}, \mathrm{Cr}, \mathrm{Mo})$ phase is provided by the observation of stripe domain structures and the hysteresis loops. The ferromagnetic state for the $\gamma_{\mathrm{N}}$ phase observed here is mainly linked to large lattice expansions $(\sim 10 \%)$ due to high $\mathrm{N}$ contents ( 30 at.\%). As an interstitial impurity, nitrogen dilates the host lattice i.e. the $\mathrm{Co}-\mathrm{Co}$ (or $\mathrm{Fe}-\mathrm{Fe}$ ) distance is increased, which strongly influences the magnetic interactions. An analogy between the magnetic properties of the expanded phases, $\gamma_{\mathrm{N}^{-}}(\mathrm{Fe}, \mathrm{Cr}, \mathrm{Ni})$ and $\gamma_{\mathrm{N}^{-}}(\mathrm{Co}, \mathrm{Cr}, \mathrm{Mo})$, formed in austenitic stainless steel alloys and the CoCrMo alloy of this study is made, and it is suggested that the ferromagnetic states for the $\gamma_{\mathrm{N}^{-}}(\mathrm{Co}, \mathrm{Cr}, \mathrm{Mo})$ and $\gamma_{\mathrm{N}^{-}}(\mathrm{Fe}, \mathrm{Cr}, \mathrm{Ni})$ phases may be correlated with the volume dependence of the magnetic properties of fcc- $-\mathrm{Co} / \mathrm{CO}_{4} \mathrm{~N}$ and fcc- $\mathrm{Fe} / \mathrm{Fe}_{4} \mathrm{~N}$, respectively.
\end{abstract}

(c) 2011 Elsevier B.V. All rights reserved.

\section{Introduction}

It is now well-established that nitrogen incorporation into the surface of austenitic stainless steels (304, 310, and 316 SS) by various ion beam methods (ion beam implantation, plasma nitriding, etc.) at moderate substrate temperatures of about $400{ }^{\circ} \mathrm{C}$ leads to a metastable, high $\mathrm{N}$ content phase, $\gamma_{\mathrm{N}}$, in the surface treated layers [1-8]. High strength (hardness values as high as $20 \mathrm{GPa}$ ), enhanced wear resistance under high loads, and enhanced corrosion resistance compared to underlying stainless steel substrate are a few important technological characteristics associated with the $\gamma_{\mathrm{N}}$ phase (also known as the expanded austenite phase) [3].

Another unusual but much less known and investigated characteristic of the $\gamma_{\mathrm{N}}$ phase is related to its magnetic nature. Depending on its $\mathrm{N}$ contents and associated lattice expansions, this phase is found to have ferromagnetic as well as paramagnetic characteristics. Previous low-energy, high-flux ion implantation research (via Mössbauer spectroscopy, MOKE and XRD) showed that the $\gamma_{\mathrm{N}}$ phase was ferromagnetically soft in nature, and was distributed in the highest $\mathrm{N}$ content region of the implantation treated layer [4]. The $\gamma_{\mathrm{N}}$ transformed to the paramagnetic state deeper into the layer as the $\mathrm{N}$ content and degree of lattice expansion decreased. The ferromagnetic

\footnotetext{
* Corresponding author. Tel.: +90 232750 7708; fax: +90 2327507707 . E-mail address: orhanozturk@iyte.edu.tr (0. Öztürk).
}

$\gamma_{\mathrm{N}}$ is attributed to an fcc structure with $\mathrm{N}$ in octahedral interstitial sites but with larger $N$ contents than the paramagnetic $\gamma_{N}$ phase [4]. Recent research [9-12] involving MFM imaging of the $\mathrm{N}$ ion beam modified austenitic SS surfaces show that the ferromagnetism in the $\gamma_{\mathrm{N}}$ phase is also revealed through the appearance of the striped domain structures with out-of-plane magnetization. Magnetic domains with in-plane magnetization have also been observed by MFM in nitrided austenitic stainless steels [12,13]. Having a magnetic $\gamma_{\mathrm{N}}$ layer on a non-magnetic substrate (underlying fcc $\gamma$ phase of austenitic SS has paramagnetic characteristics) in addition to its enhanced corrosion resistance and high strength may have industrial applications similar to those of iron nitrides which are potential candidates in high density magnetic recording applications.

Recent studies [14-18] show that a similar expanded austenite phase $\left(\gamma_{N}\right)$ can also be formed on the surface of CoCrMo alloys by a variety of ion beam surface modification techniques with significant improvements in wear and corrosion behavior of these alloys. An earlier investigation [14] by high intensity plasma ion nitriding (HIPIN) showed a characteristic expanded lattice in CoCrMo alloys near plasma nitriding temperature of $400{ }^{\circ} \mathrm{C}$. A high-flux, high-energy (60 keV) nitrogen ion implantation of a surgical grade CoCrMo alloy at the implantation temperature of $400{ }^{\circ} \mathrm{C}$ for $30 \mathrm{~min}$ demonstrated the formation of a nearly $500 \mathrm{~nm}$ thick $\gamma_{\mathrm{N}}$ layer [15]. The formation of expanded austenite structure was also demonstrated by a plasma immersion ion implantation (PIII) study [18], in which nitrogen was incorporated into an austenitic SS (304 SS) and into a CoCrMo alloy 
(Stellite 21) at moderate substrate temperatures near $400{ }^{\circ} \mathrm{C}$. This study indicated that a characteristic expanded phase, $\gamma_{N}$, could be formed in both alloy systems due to the fact that both alloy systems have a face centered cubic (fcc) structure and a high $\mathrm{Cr}$ content. The CoCrMo alloy (Stellite 21) in the PIII study [18] contains about $30 \mathrm{wt} . \%$ $\mathrm{Cr}$ and is predominantly fcc structured.

It has recently been demonstrated by us that the application of low-pressure RF plasma nitriding process to a medical grade CoCrMo alloy at $400{ }^{\circ} \mathrm{C}$ for different times leads to the expanded austenite phase, $\gamma_{N^{-}}(\mathrm{Co}, \mathrm{Cr}, \mathrm{Mo})$, in this material [19]. The results show that large lattice expansions (up to 10\%) and high hardness are a few characteristics associated with the $\gamma_{\mathrm{N}}$ phase in the CoCrMo alloy. Preliminary analysis of these surfaces by magnetic force microscopy (MFM) indicates the formation of stripe domain patterns on the nitride CoCrMo surface suggesting possible ferromagnetism in the $\gamma_{N}$ layers. The focus of the present study is to further investigate structural and magnetic characteristics of the $\gamma_{\mathrm{N}}$ layers formed on the CoCrMo alloy surface by the low-pressure RF plasma nitriding process. The magnetic behavior of the $\gamma_{\mathrm{N}}$ layers is investigated by a surface sensitive technique, magneto-optic Kerr effect (MOKE) and with a scanning probe microscope in magnetic force mode (MFM).

\section{Experimental}

A medical grade wrought low carbon cobalt-chromiummolybdenum (CoCrMo) alloy (ISO 5832-12) was the material for which the plasma nitriding was applied. The chemical composition of the alloy is given in Table 1. The formation of the expanded austenite structure in this alloy system was accomplished by a low-pressure ( 60 mTorr) Radio-Frequency plasma for $1,2,4,6$, and $20 \mathrm{~h}$ under a gas mixture of $60 \% \mathrm{~N}_{2}-40 \% \mathrm{H}_{2}$ (vol.\%). The substrate temperature was kept near $400{ }^{\circ} \mathrm{C}$ to facilitate the formation of the $\gamma_{\mathrm{N}}$ phase in this alloy system and to avoid chromium nitride precipitation in the surface treated layer. The plasma nitriding process applied here allows high rate nitriding at low temperatures without any sputtering of the sample [20]. The grain size for the specimens of this work, obtained by an earlier study [15], ranged from about 5 to $15 \mu \mathrm{m}$.

The nitrided layer phases were investigated with X-ray diffraction (XRD) in both symmetric $\theta / 2 \theta$ and grazing-incidence (GIXRD) modes using a Philips X'pert XRD system with $\mathrm{Cu}-\mathrm{K} \alpha$ radiation in the angular range from 35 to $55^{\circ}$. This scan range allows the observation of the region of the (111) and (200) peaks, which are most revealing compared to the higher (hkl) data range. Elemental depth profiles were measured by glow-discharge optical emission spectroscopy (GDOES) using a Horiba-Jobin-Yvon RF-GD profiler. Depth profiles of the elements $\mathrm{Co}, \mathrm{Cr}$, Mo and $\mathrm{N}$ were obtained. Supplemental nitrogen concentration data for the nitrided layer was also obtained by energy dispersive X-rays (EDX). Atomic force microscopy (AFM, Nanoscope IV) imaging was used to examine the surface topography and to measure roughness ( $\mathrm{Ra}$ ) for both polished (unnitrided) and plasma nitrided CoCrMo surfaces.

The magnetic structure of the plasma nitrided CoCrMo surfaces was investigated with a commercial scanning probe microscope in magnetic force mode (MFM). In this mode, a probe tip coated with a magnetic material gives an image showing the variation in the magnetic force between the magnetized probe and remnant magnetic domains in the sample surface. The MFM technique is sensitive to the magnitude and direction of the moment, but it is not possible to determine its value quantitatively in this mode. The magnetic state of

Table 1

Chemical composition of the CoCrMo substrate sample.

\begin{tabular}{lllllllllll}
\hline & $\mathrm{Cr}$ & $\mathrm{Mo}$ & $\mathrm{Mn}$ & $\mathrm{Si}$ & $\mathrm{Al}$ & $\mathrm{Ti}$ & $\mathrm{C}$ & $\mathrm{Zr}$ & $\mathrm{Fe}$ & $\mathrm{Co}$ \\
\hline wt.\% & 27.66 & 5.60 & 0.59 & 0.72 & 0.01 & 0.01 & 0.048 & 0.01 & 0.08 & $\sim 65$ \\
at.\% & 30.78 & 3.38 & 0.62 & 1.48 & 0.02 & 0.01 & 0.23 & 0.01 & 0.08 & $\sim 63$
\end{tabular}

the expanded phase $\left(\gamma_{\mathrm{N}}\right)$ was further analysed by a surface sensitive technique, longitudinal magneto-optic Kerr effect (MOKE). The effect associated with this method refers to the rotation and ellipticity induced in plane polarized light upon reflection from a magnetized surface. The sense of rotation (the Kerr rotation) is determined by the magnetization direction. The MOKE technique can be used to obtain hysteresis loops by measuring the sense of rotation as a function of the applied magnetic field in the plane of the sample. In this study, the MOKE measurements were done in longitudinal geometry in plane of the sample, so that the magnetic field is parallel to the incident laser beam. The laser spot of the MOKE apparatus was close to about $300 \mu \mathrm{m}$ so that the magnetic behavior of several grains has been assessed. Also note that the MFM analyses were performed on samples before MOKE and without any applied field.

\section{Results}

\subsection{Structural characterization}

Shown in Fig. 1 are the $\theta / 2 \theta$ XRD patterns for the substrate and plasma nitrided CoCrMo specimens. The substrate material has a predominantly fcc lattice structure [i.e., fcc $\gamma$-(Co,Cr,Mo) phase]. The XRD data for the substrate indicates peaks labeled $\varepsilon(\mathrm{hkl})$ for the hcp $\varepsilon$-(Co,Cr,Mo). Previous electron microscopy investigations [16,17] of CoCrMo alloys with similar microstructures to the one in this study show that the hcp $\varepsilon$ phase is presented as thin bands within the fcc $\gamma$-(Co,Cr,Mo) matrix. For the CoCrMo specimens nitrided for 1,2 , and $4 \mathrm{~h}$, in addition to the substrate $\gamma$ peaks, two main diffraction peaks were found at low angles. These new peaks, labeled as $\gamma_{N}(111)$ and $\gamma_{N}$ (200), are related to the formation of expanded austenite phase in the nitride CoCrMo alloy. The typical expanded austenite structure observed in austenitic stainless steel (SS) is found to have similar characteristic reflections. The XRD data in Fig. 1 show that the $\gamma_{\mathrm{N}}$ (200) peak is shifted more than the $\gamma_{N}(111)$ peak compared to the substrate $\gamma(200)$ and $\gamma(111)$ peaks, respectively, suggesting larger lattice expansion for the (200) oriented grains compared to the (111) ones. The anisotropic lattice expansion of the (111) versus the (200) $\gamma_{\mathrm{N}}$ planes parallel to the surface has also been observed in the case of nitrogen insertion into austenitic SS by ion beam methods, and is attributed mainly to different amounts of nitrogen entering into differently oriented grains as well as to compressive stresses. The anisotropic lattice expansion, thought to be a $\gamma_{\mathrm{N}}$ phase characteristic, has been discussed in detail elsewhere [4].

With increasing nitriding times ( 6 and $20 \mathrm{~h}$ ), the nitrided layer is mainly composed of the $\gamma_{\mathrm{N}}$ phase. However, the XRD data clearly indicate some structural changes taking place for the 6 and $20 \mathrm{~h}$

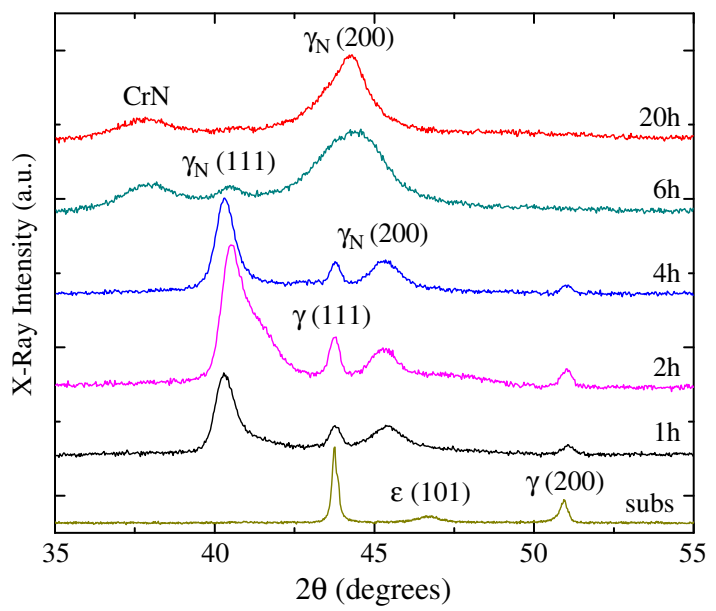

Fig. 1. XRD data for the CoCrMo alloy specimen plasma nitrided at a substrate temperature of $400{ }^{\circ} \mathrm{C}$ for $1,2,4,6$, and $20 \mathrm{~h}$. The substrate $\mathrm{CoCrMo}$ data is also included. 
nitrided samples. The data for these samples shows a weak and nonexistent $\gamma_{N}(111)$ peak, while the $\gamma_{N}(200)$ peak becomes stronger, very broad, and is shifted to even much lower angles (larger lattice expansion). These results suggest a preferential (200) orientation of $\gamma_{\mathrm{N}}$ grains parallel to the surface with increasing nitriding times. A recent plasma nitriding study [21] of an austenitic SS (316L) for very long times at $400{ }^{\circ} \mathrm{C}$ reported the change of the crystallographic orientation due to nitriding, and attributed the orientation change (i.e., texture evolution) to high compressive residual stresses in the nitrided layer that developed as a consequence of large lattice expansions $(\sim 9 \%)$ in the fcc substrate matrix. As is quantifed below, the lattice expansions observed in the nitrided CoCrMo alloy in this work is $\sim 10 \%$. The longer time nitriding data also reveals the existence of a new peak associated with CrN. The GIXRD data (not presented here) clearly indicates that $\mathrm{CrN}$ phase is distributed quite homogenously within the $\gamma_{\mathrm{N}}$ layer since the GIXRD analysis shows no significant variation of the $\mathrm{CrN}$ peak intensity with the X-ray penetration depth variation. The very broad nature of the (200) $\gamma_{N}$ peak also suggests a fine dispersion of $\mathrm{CrN}$ particles in the $\gamma_{\mathrm{N}}$ matrix.

Analyses of the $\gamma$ and $\gamma_{N}$ XRD peak positions (Fig. 1) on the basis of the fcc lattice yields the lattice constant values listed in Table 2. Fits were made to each peak with one or more Pearson VII functions to obtain accurate peak centers (i.e., the lattice parameters via Bragg's equation). More details related to the quantitative XRD analyses can be found in Ref. [4]. As can be seen from this table, nitrogen insertion into the CoCrMo alloy by plasma nitriding results in much larger lattice constants in comparison to that of the substrate alloy. Note the large difference in the (111) and (200) lattice parameters. As discussed previously $[3,4,10]$, this difference in lattice expansion for the different planes parallel to the surface is mainly due to higher $\mathrm{N}$ contents in the (200) planes relative to the (111) ones. The difference is also attributed to residual, in-plane stress in the $\gamma_{\mathrm{N}}$ layer. As can be seen from Table 2, the $\gamma_{\mathrm{N}}$ lattice constant values compared to those of the substrate fcc $\gamma$-(Co,Cr,Mo) phase are about $10 \%$ higher and such values are quite likely to induce compressive stresses in the $\gamma_{N}$ layers.

Fig. 2 presents the $\mathrm{N}$ concentration profiles obtained by GDOES for the samples nitrided for 2, 6 and $20 \mathrm{~h}$. The $\mathrm{N}$ concentration values are quite high at the surface (ranging from $\sim 28$ to $~ 32$ at.\%) and then they decrease almost linearly but in a slow fashion to a level of $\sim 20$ at.\%, and then decrease exponentially. The non-error function shape of the profiles suggest enhanced nitrogen diffusion under the influence of traps, which are probably formed by the chromium alloying element in the CoCrMo alloy $[3,22]$. The $\mathrm{N}$ profiles observed here are quite similar to the $\mathrm{N}$ concentration-depth profiles in austenitic stainless steels surface treated near $400{ }^{\circ} \mathrm{C}[10,22]$. The $\mathrm{N}$ content values for the plasma nitride layers were also determined by energy dispersive $\mathrm{X}$-rays (EDX). The EDX results, listed in Table 3, indicate that the average $\mathrm{N}$ content of the $\gamma_{\mathrm{N}}$ layers is about 25 at.\%.

\subsection{Magnetic behavior}

The magnetic nature of the $\gamma_{\mathrm{N}}$ layers on CoCrMo alloy was probed by magnetic force microscopy (MFM) and magneto-optic Kerr effect

\section{Table 2}

Lattice parameters, a, in $\AA$ for the CoCrMo alloy fcc $\gamma$ substrate phase and the fcc $\gamma_{N}$ phase. $\Delta \mathrm{a} / \mathrm{a}$ refers to the relative difference in lattice spacing and is given by $\Delta \mathrm{a} / \mathrm{a}=$ $\left[\left\{\mathrm{a}\left(\gamma_{\mathrm{N}}\right)-\mathrm{a}(\gamma)\right\} / \mathrm{a}(\gamma)\right]$.

\begin{tabular}{llllll}
\hline Time $(\mathrm{h})$ & phases & $\mathrm{a}_{(111)}(\AA)$ & $\mathrm{a}_{(200)}(\AA)$ & $<\mathrm{a}>(\AA)$ & $\Delta \mathrm{a} / \mathrm{a}(\%)$ \\
\hline Substrate & $\gamma, \varepsilon$ & 3.583 & 3.589 & 3.586 & - \\
1 & $\gamma_{\mathrm{N}}$ & 3.863 & 3.982 & 3.922 & 9.4 \\
2 & $\gamma_{\mathrm{N}}$ & 3.860 & 4.004 & 3.932 & 9.6 \\
4 & $\gamma_{\mathrm{N}}$ & 3.863 & 3.998 & 3.930 & 9.6 \\
6 & $\gamma_{\mathrm{N}}, \mathrm{CrN}$ & 3.859 & 4.091 & 3.975 & 10.8 \\
20 & $\gamma_{\mathrm{N}}, \mathrm{CrN}$ & 3.857 & 4.091 & 3.974 & 10.8 \\
\hline
\end{tabular}

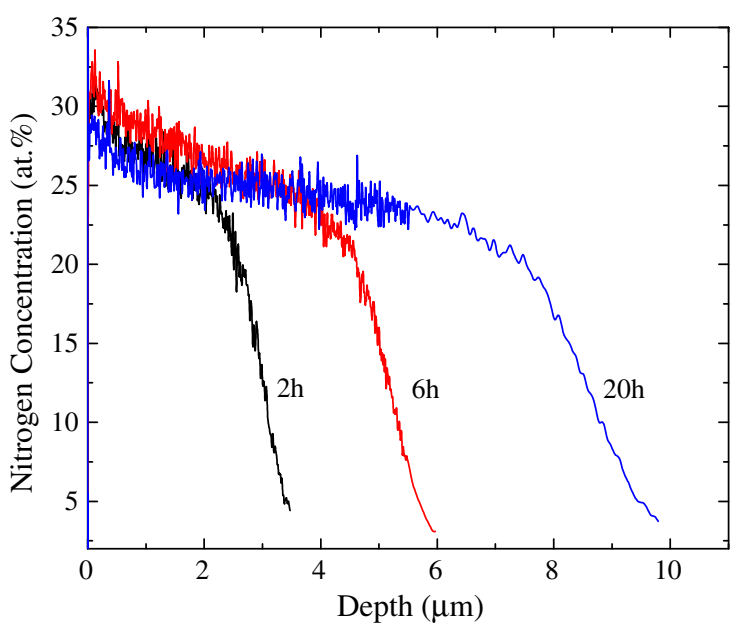

Fig. 2. GDOES nitrogen depth profiles of the plasma nitrided specimens.

(MOKE). Fig. 3 displays a series of MFM images taken on the nitrided surfaces. The dark and light bands in these images are characteristic signature of the remnant magnetic domains present. The ferromagnetism in the $\gamma_{\mathrm{N}}$ layers is revealed through the appearance of the striped (or maze-like) domains. The patterns observed here are typical of the vertical domains found in a number of materials in thin film form. According to literature [23,24], a stripe domain structure is a clear evidence for a significant magnetization vector directed off the sample surface.

The MFM images in Fig. 3 show the diversity of the magnetic domains in the $\gamma_{\mathrm{N}}$ layers as a function of the nitriding time. It seems the domain size increases as the processing time increases. For the samples nitrided for 6 and $20 \mathrm{~h}$, in the MFM images there are also regions with poor magnetic contrast. For these regions the magnetization probably lies in-plane (i.e., the presence of in-plane magnetic domains). The variation in the size and form of the magnetic domains from grain-to-grain (and also from one sample to another) may be due to non-uniform $\mathrm{N}$ contents and different amounts of lattice expansions in the different grains as found from the quantitative XRD data in Table 2.

MFM images are not easy to analyze. The surface roughness of the nitrided surfaces (see Table 3 ), the $\gamma_{N}$ layer thicknesses (Table 3), and CrN precipitates that are distributed in the $\gamma_{\mathrm{N}}$ layer for the samples nitrided for 6 and $20 \mathrm{~h}$, are not taken into account. Experimental studies of magnetic materials in thin film form suggest in-plane to out-of-plane magnetic domain behavior as the thickness of the films increase [24]. Larger domain size and different domain morphology observed for the 6 and $20 \mathrm{~h}$ samples may be due to thicker $\gamma_{\mathrm{N}}$ layers and due to the distribution of $\mathrm{CrN}$ particles within the $\gamma_{\mathrm{N}}$ matrix. A recent investigation [25] of magnetic and structural properties of an ion nitrided 316 SS suggest that magnetic domain pattern variations can be associated with crystal anisotropy, grain boundary, crystalline

Table 3

Mean roughness, Ra, was measured by AFM. Average nitrided layer thicknesses were measured by SEM on the electrochemically etched sample cross-sections and Ar beam etched cross-sections (values in parentheses). The $\mathrm{N}$ content values measured by EDX are listed in this table for a comparison to the GDOES analysis results in Fig. 2.

\begin{tabular}{lcll}
\hline Time $(\mathrm{h})$ & Ra $(\mathrm{nm})$ & $\mathrm{L}_{\text {SEM }}(\mu \mathrm{m})$ & N content $($ at.\%) \\
\hline Substrate & 3.6 & - & - \\
1 & 29.4 & $(2.22)$ & 24.9 \\
2 & 30.0 & $1.67(2.04)$ & 25.7 \\
4 & 45.6 & $(2.80)$ & 24.8 \\
6 & 46.2 & $4.90(3.93)$ & 24.0 \\
20 & 60.1 & $10.25(11.06)$ & 25.4 \\
\hline
\end{tabular}



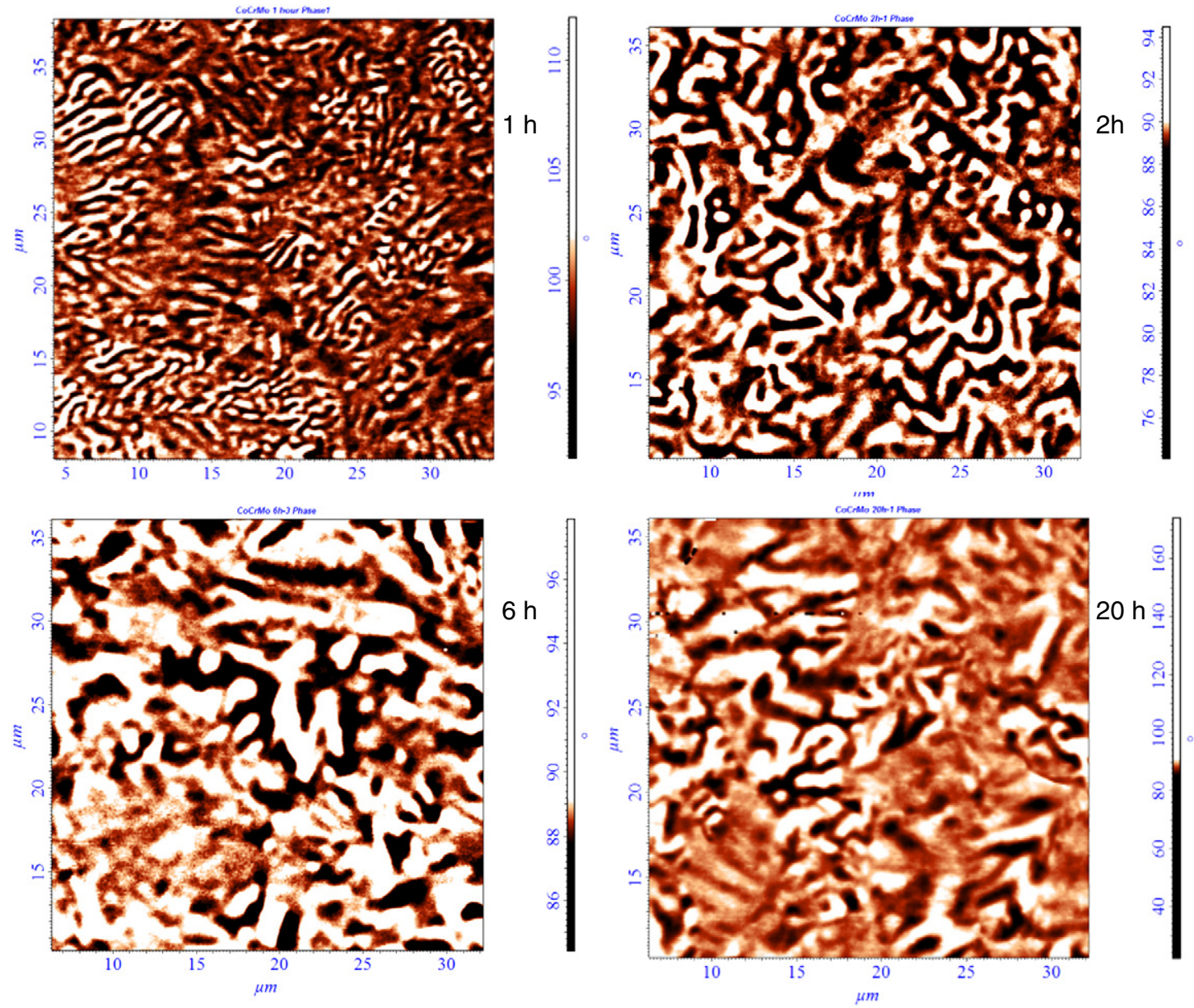

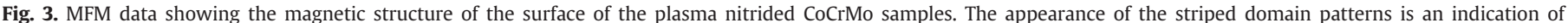
ferromagnetism in the nitride surfaces. The image scan area was $35 \mu \mathrm{m} \times 35 \mu \mathrm{m}$.

defects, and local deformation. Another plasma nitriding study of $316 \mathrm{~L}$ SS via MOKE and MFM [12], at a more fundamental level, attributes different domain morphologies (variation in the size and form) mainly to the balance between exchange, anisotropy, and dipolar energies.

The magnetic behavior of the $\gamma_{\mathrm{N}}$ layers on the CoCrMo substrate material was also investigated by magneto-optic Kerr effect (MOKE). Fig. 4 shows the experimental MOKE results from the plasma nitrided

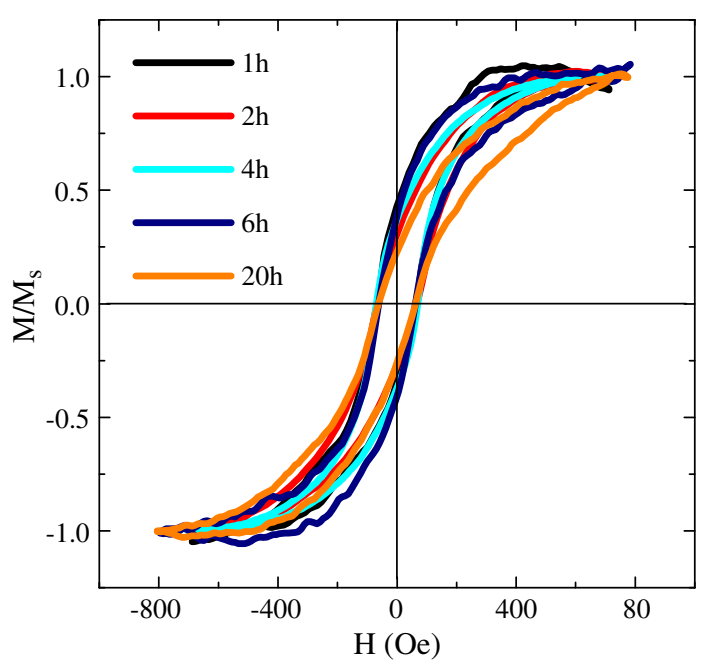

Fig. 4. Hysteresis loops obtained by MOKE measurements for the nitrided specimens.
CoCrMo samples. The hysteresis loops for the plasma nitrided specimens clearly demonstrate ferromagnetic type behavior. The observed loop behavior for all the samples is a sheared one with relatively small coercivity $\left(\mathrm{H}_{\mathrm{C}}\right)$. The characteristics shown by the hysteresis loops for the plasma nitrided CoCrMo alloy specimens are similar to that of a softer ferromagnet.

\section{Discussion}

The experimental findings above clearly show that the application of RF plasma nitriding to a CoCrMo alloy at $400{ }^{\circ} \mathrm{C}$ for different processing times results in an expanded austenite-like phase, $\gamma_{\mathrm{N}^{-}}(\mathrm{Co}$, $\mathrm{Cr}, \mathrm{Mo})$, in this material. A few important characteristics associated with the $\gamma_{\mathrm{N}}$ phase in the CoCrMo alloy demonstrated in this study are large lattice expansions ( $10 \%)$, non-error-function type of nitrogen concentration-depth profiles, and ferromagnetic type of magnetic behavior. The characteristics mentioned above are already wellestablished for the expanded austenite phase, $\gamma_{N^{-}}(\mathrm{Fe}, \mathrm{Cr}, \mathrm{Ni})$ in austenitic stainless steels, i.e. FeCrNi alloys. The $\gamma_{N^{-}}(\mathrm{Fe}, \mathrm{Cr}, \mathrm{Ni})$ is formed by ion beam methods such as ion implantation, plasma nitriding, etc. at a substrate temperature around $400{ }^{\circ} \mathrm{C}$. The $\gamma_{\mathrm{N}^{-}}(\mathrm{Co}$, $\mathrm{Cr}, \mathrm{Mo})$ formation in the CoCrMo alloy of this study and its associated characteristics are also quite consistent with recent studies in which nitrogen was inserted into this type of alloy at substrate temperatures in the range from 370 to $450{ }^{\circ} \mathrm{C}$ for different processing times by conventional high-flux nitrogen ion implantation [15], plasma nitriding processes known as high intensity plasma nitriding (HIPIN) [14], plasma alloying [16,17], and plasma immersion ion implantation (PIII) [18]. 
As explained by the plasma alloying and PIII studies, the $\gamma_{N^{-}}(\mathrm{Co}, \mathrm{Cr}$, Mo) formation in the CoCrMo alloy of this study and the $\gamma_{N^{-}}(\mathrm{Fe}, \mathrm{Cr}, \mathrm{Ni})$ formation in austenitic stainless steel alloys can be attributed to common structural features and chemical similarities between the two alloy systems. While an FeCrNi alloy such as 304 SS or 316L SS has face centered cubic structure only, the CoCrMo alloy of this study is predominantly fcc structured (the alloy has also hcp structure). Note that while the fcc CoCrMo alloy of this study has a lattice constant of $0.3586 \mathrm{~nm}$, the lattice constant for the 316L SS alloy that was plasma nitrided under conditions similar to the ones in this work is $0.3573 \mathrm{~nm}$ [11]. The $\gamma_{\mathrm{N}}$ lattice constants for the two alloys are $0.3932 \mathrm{~nm}$ and $0.3929 \mathrm{~nm}$, respectively. In addition to structural similarity, there are chemical similarities between the two alloy systems. Both alloy systems rely on high chromium contents for their corrosion resistance. While the CoCrMo alloy in this study has about 30 at.\% Cr, the 316L SS alloy in Ref. [11] has 18-19 at.\% Cr. Chromium affects the solubility and mobility of nitrogen in the two alloy systems. The GDOES profiles above suggest enhanced nitrogen diffusion under the influence of traps, which are probably formed by the chromium alloying element in the CoCrMo alloy. The plateau-type profiles observed in the CoCrMo alloy at $400{ }^{\circ} \mathrm{C}$ are quite similar to the $\mathrm{N}$ depth profiles in austenitic stainless steels.

The most important finding in this research is the ferromagnetic type of behavior for the $\gamma_{N^{-}}(\mathrm{Co}, \mathrm{Cr}, \mathrm{Mo})$ layer on the CoCrMo substrate alloy. In this study, the ferromagnetism in the $\gamma_{\mathrm{N}}$ layers is revealed by the observation of stripe domain structures in the MFM images and by the hysteresis loops obtained via MOKE analysis. The ferromagnetic ordering for the fcc high $\mathrm{N}$ phase $\left(\gamma_{\mathrm{N}}\right.$ phase) in the CoCrMo alloy of this study is mainly linked to large lattice expansions $(\sim 10 \%)$ due to high $\mathrm{N}$ contents ( 28 to 32 at.\%) in the nitrided layers.

There exists a few studies related to the magnetic nature of the expanded austenite phase, $\gamma_{\mathrm{N}^{-}}(\mathrm{Fe}, \mathrm{Cr}, \mathrm{Ni})$, formed in the $\mathrm{FeCrNi}$ alloys while there is no such study to our knowledge for the expanded phase, $\gamma_{N^{-}}(\mathrm{Co}, \mathrm{Cr}, \mathrm{Mo})$ in the CoCrMo alloy. One of the first studies [2] reporting ferromagnetism for the $\gamma_{\mathrm{N}}$ phase was an ion nitriding investigation of $304 \mathrm{SS}$ at $400{ }^{\circ} \mathrm{C}$. The pioneering work [4] of Öztürk and Williamson, involving low-energy, high-flux $\mathrm{N}$ implantation of $304 \mathrm{SS}$ at $400{ }^{\circ} \mathrm{C}$, revealed important details related to the magnetic nature of the $\gamma_{\mathrm{N}}$ phase. This study (via Mössbauer spectroscopy and MOKE analyses) showed that the $\gamma_{\mathrm{N}}$ phase had the magnetic properties of a soft magnetic material and was distributed in the highest $\mathrm{N}$ concentration ( 30 at.\%) (and associated lattice expansion $\sim 10 \%$ ) region of the $\mathrm{N}$ implanted layer. This study showed that further into the implanted layer the $\gamma_{\mathrm{N}}$ phase transformed to the paramagnetic $\gamma_{\mathrm{N}}$ state as the $\mathrm{N}$ content $(\sim 20$ at.\% and less) and lattice expansion decreased.

More recently, the magnetic character of the $\gamma_{\mathrm{N}}$ phase has been studied by magnetic force microscopy (MFM) [9-12]. According to these MFM analyses, the ferromagnetism in the $\gamma_{\mathrm{N}}$ layers on austenitic stainless steels is revealed via the observation of stripe domain structures. One of these MFM works [10] indicated that the $\gamma_{\mathrm{N}}$ magnetic behavior changed from one polycrystalline grain to another. This variation was explained by the non-uniform $\mathrm{N}$ contents and different amounts of lattice expansion in the differently oriented grains. A more recent plasma nitriding study of 316L polycrystalline austenitic stainless steel (via MFM and MOKE analyses) verified that the magnetic response of nitrogen-enriched grains is correlated to their crystallographic orientation [12].

The ferromagnetic ordering for both $\gamma_{\mathrm{N}}$ phases, $\gamma_{\mathrm{N}^{-}}(\mathrm{Fe}, \mathrm{Cr}, \mathrm{Ni})$ in austenitic stainless steels and $\gamma_{\mathrm{N}^{-}}(\mathrm{Co}, \mathrm{Cr}, \mathrm{Mo})$ in the CoCrMo alloy of this study, is also supported by other research in which hydrogen is incorporated into the fcc lattice by different methods. An earlier study [26] of hydrogen addition into fcc stainless steel by cathodic charging showed that the fcc-SS phase was stable but expanded by $\mathrm{H}$ in interstitial sites and exhibited ferromagnetic ordering with a subambient Curie temperature $\left(T_{C}\right)$. The lattice parameter of the fcc hydride $\left[\gamma_{\mathrm{H}^{-}}(\mathrm{Fe}, \mathrm{Cr}, \mathrm{Ni})\right.$ phase] was $5 \%$ larger than that of the uncharged material. A much more recent study [27], in which hydrogenation of 304 and 310 SS samples was done in a highpressure cell at $350{ }^{\circ} \mathrm{C}$ for $24 \mathrm{~h}$ under pressures of up to $7 \mathrm{GPa}$, showed that the hydrogenation of both steels resulted in a pure expanded fcc lattice and that both steels become ferromagnetic at high hydrogen concentrations. The conclusion of this study was that hydrogenation leads to lattice expansion, the Fe-Fe distance is increased, which strongly influences the magnetic interactions. These experimental observations are also supported by band structure calculations [28].

The magnetic nature of the expanded phases, $\gamma_{\mathrm{N}^{-}}(\mathrm{Co}, \mathrm{Cr}, \mathrm{Mo})$ and $\gamma_{\mathrm{N}^{-}}(\mathrm{Fe}, \mathrm{Cr}, \mathrm{Ni})$ [and $\gamma_{\mathrm{H}^{-}}(\mathrm{Fe}, \mathrm{Cr}, \mathrm{Ni})$ as just discussed] can be explained on the basis of the magnetic properties of face centered cubic (fcc) $\gamma$-Fe. It is known that the magnetic properties of fcc $\gamma$-Fe are particularly sensitive to lattice volume, and the magnetic states may be found which have a high moment, a low moment or are non-magnetic according to the lattice parameter. Theoretical work on the volume dependence of the magnetic moment of $\gamma$-Fe show a high volume, high-spin state (ferromagnetic state of fcc-Fe) along with a lowvolume, low-spin state (antiferromagnetic state of fcc-Fe) [29-31]. The volume dependence of the magnetic properties of fcc-Fe suggests ferromagnetic behavior for the $\gamma_{\mathrm{N}}-(\mathrm{Fe}, \mathrm{Cr}, \mathrm{Ni})$ due to large lattice expansion.

As for physical reasons of ferromagnetism in the expanded phases, the origin comes from electronic structure of Fe (for stainless steel) or Co atoms (for CoCrMo alloy) and more precisely from 3d orbitals. It is known that the strength of Fe-Fe magnetic exchange interactions are strongly dependent on the orbital overlap i.e. the interatomic distance. It is likely that the lattice expansion due to the introduction of nitrogen atoms into the octahedral sites modifies the electronic structure of Fe or Co (expanding the lattice reduces the 3d-3d overlap enhancing Fe or Co magnetic moments). It is also necessary to take into account the effect of the hybridization of the interstitial nitrogen atoms with the neighboring host $\mathrm{Fe}$ or $\mathrm{Co}$ atoms to explain the origin of ferromagnetism in the expanded phases. Literature [32] indicates that the introduction of nitrogen into iron is to modify the 3d density of states and to reduce the difference in occupancy of the $3 \mathrm{~d}$ up and down states due to hybridization with the sp orbitals of nitrogen.

The magnetism of the expanded phase $\left[\gamma_{\mathrm{N}^{-}}(\mathrm{Fe}, \mathrm{Cr}, \mathrm{Ni})\right]$ is probably related to the ferromagnetic state of $\gamma^{\prime}-\mathrm{Fe}_{4} \mathrm{~N}$, which has a much expanded lattice compared to fcc-Fe and is ferromagnetic at room temperature [4]. Previous research shows that the onset to ferromagnetism in $\gamma_{\mathrm{N}}-(\mathrm{Fe}, \mathrm{Cr}, \mathrm{Ni})$ occurs for lattice parameters and $\mathrm{N}$ contents (near 20 at.\%) similar to that of $\gamma^{\prime}-\mathrm{Fe}_{4} \mathrm{~N}$. It appears that the $\mathrm{N}$ content has to be above some critical concentration to produce this magnetic modification in the $\gamma_{\mathrm{N}}$. Earlier ion implantation research [4] by Mössbauer analysis shows that only the most concentrated region of the nitrogen treated layer is ferromagnetic while the $\gamma_{\mathrm{N}}$ phase with paramagnetic characteristics, with less lattice expansions and lower $\mathrm{N}$ contents, becomes predominant into the treated layer.

By analogy, the magnetism of the expanded phase $\gamma_{\mathrm{N}^{-}}(\mathrm{Co}, \mathrm{Cr}, \mathrm{Mo})$ could be attributed to the cobalt nitride, fcc $\mathrm{Co}_{4} \mathrm{~N}$, which has similar crystal structure to that of fcc- $\mathrm{Fe}_{4} \mathrm{~N}$ (both structures can be described as a face centered cubic lattice of iron (cobalt) metal with a nitrogen atom inserted at the body center). Recent band structure calculations performed for the two nitrides, $\mathrm{Fe}_{4} \mathrm{~N}$ and $\mathrm{Co}_{4} \mathrm{~N}$, demonstrate a lowvolume-low moment and large-volume-high-moment behavior for fcc$\mathrm{Co} / \mathrm{Co}_{4} \mathrm{~N}$ (like in $\mathrm{fcc}-\mathrm{Fe} / \mathrm{Fe}_{4} \mathrm{~N}$ ) $[33,34]$. These calculations suggest that the enhancement of the corner site magnetic moments FeI or CoI ( in the fcc unit cell FeI or CoI atoms occupy the corners of the cubic unit cell and the FeII or CoII atoms occupy the face center of the unit cube), with respect to their values in metallic iron and cobalt, is due to the cell volume expansion caused by the nitrogen insertion. In other words, the nitrogen insertion increases the volume available for the iron or cobalt atoms at the corners in comparison with the face centered sites, and this results in the corresponding high moment 
values (the properties of FeI or CoI should be closer to those of the high-spin fcc-Fe or fcc-Co state at a large volume). On the other hand, the low values of face centered moments (FeII or CoII) are due to their strong covalent bond formed with $\mathrm{N}$ atom and due to the low-volume generated by $\mathrm{N}$ insertion in those sites (the properties of FeII or CoII should be similar to the low-spin state at a low-volume of fcc-Fe or fcc-Co). Here, we find evidence of the high volume, high moment, ferromagnetic, fcc-Fe or fcc-Co state in the expanded phases.

\section{Conclusions}

This study investigated structural and magnetic character of the expanded phase $\left(\gamma_{\mathrm{N}}\right)$ layer formed on CoCrMo alloy by a low-pressure RF plasma nitriding process. The $\gamma_{\mathrm{N}}$ formation in this alloy system was facilitated at a substrate temperature near $400{ }^{\circ} \mathrm{C}$ for various nitriding times. The expanded phase formation in the CoCrMo alloy of this study and those formed in austenitic stainless steel alloys (304 SS and 316L SS) were compared from the structural similarity (both alloy systems with fcc structure) and chemical similarity (high $\mathrm{Cr}$ contents for both alloy systems) viewpoints. Strong evidence for the ferromagnetic nature of the $\gamma_{\mathrm{N}^{-}}(\mathrm{Co}, \mathrm{Cr}, \mathrm{Mo})$ phase is provided by combined MFM and MOKE analyses. According to these analyses, ferromagnetism in the $\gamma_{N}$ layers is revealed by the observation of stripe domain structures and the hysteresis loops. The ferromagnetic state for the $\gamma_{N}$ phase observed here is mainly linked to large lattice expansions $(\sim 10 \%)$ due to high $\mathrm{N}$ contents ( 30 at.\%). An analogy between the magnetic properties of the expanded phases, $\gamma_{\mathrm{N}^{-}}(\mathrm{Fe}, \mathrm{Cr}, \mathrm{Ni})$ and $\gamma_{\mathrm{N}^{-}}$ ( $\mathrm{Co}, \mathrm{Cr}, \mathrm{Mo})$, formed in austenitic stainless steel alloys and the CoCrMo alloy of this study is made, and it is suggested that the ferromagnetic states for the $\gamma_{\mathrm{N}^{-}}(\mathrm{Co}, \mathrm{Cr}, \mathrm{Mo})$ and $\gamma_{\mathrm{N}^{-}}(\mathrm{Fe}, \mathrm{Cr}, \mathrm{Ni})$ phases may be correlated with the volume dependence of the magnetic properties of fcc- $\mathrm{Co} / \mathrm{Co}_{4} \mathrm{~N}$ and fcc-Fe/ $/ \mathrm{Fe}_{4} \mathrm{~N}$, respectively.

\section{Acknowledgments}

The authors would like to thank TIPSAN for providing medical grade CoCrMo materials for this study. The research carried out in this study was funded by Turkish National Science Foundation (Tubitak) through grant 107M218. This is a joint project between the National Science Foundations of Turkey and France (project PIA Bosphorus).

\section{References}

[1] Z.L. Zhang, T. Bell, Surf. Eng. 1 (1985) 131.

[2] K. Ichii, K. Fujimura, T. Takase, Technol. Reports Kansai Univ., Vol. 127, 1986, p. 134.

[3] D.L. Williamson, O. Ozturk, R. Wei, P.J. Wilbur, Surf. Coat. Technol. 65 (1994) 15.

[4] O. Ozturk, D.L. Williamson, J. Appl. Phys. 77 (1995) 3839.

[5] G.A. Collins, R. Hutchings, K.T. Short, J. Tendys, M. Samandi, Surf. Coat. Technol. $74-75$ (1995) 417.

[6] S. Parascandola, R. Günzel, R. Grötzshel, E. Richter, W. Möller, Nucl. Instrum. Meth. Phys. Res. B 136-138 (1998) 1281.

[7] J.P. Riviere, P. Meheust, J.P. Villain, C. Templier, M. Cahoreu, G. Abrasonis, L. Pranevicius, Surf. Coat. Technol. 158-159 (2002) 99

[8] S. Mändl, B. Rauschenbach, J. Apply. Phys. 88 (2000) 3323.

[9] M.P. Fewell, D.R.G. Mitchell, J.M. Priest, K.T. Short, G.A. Collins, Surf. Coat. Technol. 131 (2000) 300.

[10] D.L. Williamson, P.J. Wilbur, F.R. Fickett, S. Parascandola, Stainless Steel 2000, in: T. Bell, K. Akkamatsu (Eds.), Proceedings of an International Current Status Seminar on Thermochemical Surface Engineering of Stainless Steels, The Institute of Materials, London, 2001, p. 333.

[11] O. Öztürk, S. Okur, J.P. Riviere, Nucl. Instrum. Method B 8-9 (2009) 1540

[12] E. Menendez, J.C. Stinville, C. Tromas, C. Templier, P. Villechaise, J.P. Riviere, M. Drouet, A. Martinavicius, G. Abrasonis, J. Fassbender, M.D. Baro, J. Sort, J. Nogues, Appl. Phys. Lett. 96 (2010) 242509.

[13] E. Menendez, A. Martinavicius, M.O. Liedke, G. Abrasonis, J. Fassbander, J. Sommerlatte, K. Nielsch, S. Surinach, M.D. Baro, J. Nogues, J. Sort, Acta Materiale 56 (2008) 4570.

[14] B.R. Lanning, R. Wei, Surf. Coat. Technol. 186 (2004) 314.

[15] O. Öztürk, U. Türkan, A.E. Eroglu, Surf. Coat. Technol. 200 (2006) 5687.

[16] X.Y. Li, N. Habibi, T. Bell, H. Dong, Surf. Eng. 23 (2007) 45.

[17] J. Chen, X.Y. Li, T. Bell, H. Dong, Wear 264 (2008) 157.

[18] J. Lutz, J.W. Gerlach, S. Mändl, Phys. Stat. Sol. A 205 (2008) 980.

[19] L. Pichon, S. Okur, O. Öztürk, J.P. Riviere, M. Drouet, Surf. Coat. Technol. 204 (2010) 2913.

[20] L. Marot, A. Straboni, M. Drouet, Surf. Coat. Technol. 142-144 (2001) 384.

[21] J.C. Stinville, P. Villechaise, C. Templier, J.P. Riviere, M. Drouet, Acta Mater. 58 (2010) 2814

[22] S. Parascandola, W. Möller, D.L. Williamson, Apply. Phys. Lett. 76 (2000) 2194.

[23] Y.S. Chun, K.M. Krishnan, J. Appl. Phys. 95 (2004) 6858.

[24] M. Coisson, F. Vinai, P. Tiberto, F. Celegato, J. Mag. Mag. Mater. 321 (2009) 806.

[25] R.L.O. Basso, V.L. Pimental, S. Weber, G. Marcos, T. Czerwiec, I.J.R. Baumvol, C.A. Figuerova, J. Appl. Phys. 105 (2009) 124914.

[26] N. Narita, C.J. Altstetter, H.K. Birnbaum, Metall. Trans. A 113 (1982) 1355.

[27] M. Hoelzel, S.A. Danilkin, H. Ehrenberg, D.M. Toebbens, T.J. Udovic, H. Fuess, H. Wipf, Mater. Sci. Eng. A 384 (2004) 255.

[28] A.G. Vakhney, A.N. Yaresko, V.N. Antonov, V.V. Nemoshkalenko, Int. J. Hydrogen Energy 26 (2001) 453.

[29] M. Uhl, M. Sandratskii, J. Kübler, Phys. Rev. B 50 (1994) 291.

[30] V.L. Moruzzi, P.M. Marcus, K. Schwarz, P. Mohn, Phys. Rev. B 34 (1986) 1784

[31] P. Mohn, S.F. Matar, J. Mag. Mag. Mater. 191 (1999) 234.

[32] J.M.D. Coey, P.A.I. Smith, J. Mag. Mag. Mater. 200 (1999) 405

[33] S.F. Matar, A. Houari, M.A. Belkhir, Phys. Rev. B 75 (2007) 245109.

[34] A. Houari, S.F. Matar, M.A. Belkhir, J. Mag. Mag. Mater. 322 (2010) 658. 